\title{
Metrópole e cultura o novo modernismo paulista em meados do século
}

\author{
MARIA ARMINDA DO NASCIMENTO ARRUDA
}

RESUMO: O artigo se propõe analisar a cultura na cidade de São Paulo, em meados do século, enfatizando o caráter singular das linguagens no período. A particularidade resulta da presença de um tecido cultural plural, no qual os próprios intelectuais e artistas viam-se como introdutores de profundas rupturas em relação ao legado do modernismo do anos 20 . Sem se constituir em experiência pura exclusiva, germinou na cidade de São Paulo uma perspectiva essencial que se poderia denominar de novo modernismo, respaldado numa substância cultural heterogênea e múltipla, atrelado a uma realidade interligada ao movimento exterior. A cultura paulistana, nesse período, identifica-se com as concepções de progresso, da possibilidade de formação de um futuro civilizado e internacionalmente articulado, nos mais diversos campos da expressão: nas ciências sociais, nas artes plásticas, na poesia, na arquitetura, no teatro, no cinema, na mídia.

lorestan Fernandes em texto escrito para o Congresso Internacional de Americanistas, realizado em 1954, no âmbito das comemorações do IV Centenário de São Paulo, traduziu lapidarmente o sentimento comum que ocupava os habitantes da cidade nesse momento: "O passado possui pouca significação. O que importa é o presente e, acima de tudo, o futuro" (Fernandes, 1974a, p. 201). E de fato, se quisermos expressar a percepção difundida em amplas parcelas dos paulistanos quanto à dinâmica acelerada de transformação da capital, encontraremos valorizações altamente positivas a envolver adesão ao novo estilo urbano que se impunha. Inclinações dessa natureza apanhavam a complexa história da metropolização de São Paulo que, no transcurso dos anos 50-60, delineava um ponto de inflexão ${ }^{1}$.

Se essas manifestações revelavam a condensação de outro tipo de sensibilidade urbana conectada à vida da metrópole, isto é, da emergência de
UNITERMOS:

cultura,

São Paulo, novo modernismo, anos 50.

Professora do Departamento de Sociologia da FFLCH-USP 
1 "No entanto, apesar destas variações no que diz respeito ao 'momento exato' da emergência da metrópole e das inflexões de sua trajetória - de cidade à metrópole todos apontam para uma etapa decisiva em São Paulo no decênio 50-60" (Meyer, 1991, p. 9). formas novas de sociabilidade, do ponto de vista da formação sociocultural da cidade ocorria, de fato, uma clivagem. "A disposição subjetiva dominante não só envolve a aceitação, como a supervalorização das condições urbanas de existência social" (Meyer, 1991, p. 206). Em outros termos, encontra-se em processo de cristalização um problema cultural de ordem diversa, no qual o peso normativo do passado é afastado e o presente erige-se na principal referência, momento da vivência das possibilidades infinitas da vida moderna, cuja experiência tenderia a se alargar no futuro. A expressão última subjacente àquele sentimento difundido em meados dos anos 50 na cidade de São Paulo diz respeito a um reconhecimento, ou talvez a uma vontade, de que se vivia a suspensão de uma história, um verdadeiro corte em relação ao passado. A aposta nesse momento ultrapassava o universo do cidadão comum e abrangia as análises realizadas sobre a revolução que se operava na cidade: "a urbanização representa e assegura a evolução para situações sociais de vida historicamente desejáveis no Brasil" (Meyer, 1991, p. 206).

A ênfase no presente resulta na crença em um futuro promissor identificado, neste caso, com a realidade de uma sociedade de classes aberta e com um regime de participação democrática. A cidade burguesa que emergira nos fins do século XIX atingia, após meio século, genuíno estilo urbano de vida, ligado a um universo valorativo de ordem diversa, respaldado na idéia de progresso inelutável. "Como a história não se faz em um dia, aí temos mais uma evidência de que o nosso presente é rico de forças que trabalham para um futuro melhor. Os que pensam no Brasil como 'país de futuro' têm em vista, naturalmente, cidades como São Paulo, nas quais se está forjando, verdadeiramente, a sociedade brasileira da era científica e tecnológica" (Fernandes, 1974a, p. 303). A afirmação do progresso, reconhecido na interpenetração da ciência e da tecnologia, já revelava os princípios da cultura que se gestava na cidade. Ao mesmo tempo em que o passado era abjurado, impondo a construção de novos princípios identitários a grupos sociais inteiros, a perspectiva do futuro estava ancorada na concepção do progresso recéminiciado. "Paradoxalmente, o esforço de lançar fora os grilhões da história acelerou os processos históricos, pois a indiferença por qualquer relação com o passado libera a imaginação, permitindo que proliferem novas formas e novas construções. Inversamente, a consciência da rápida transformação presente enfraquece a autoridade da história como passado relevante" (Schorske, 1988, p. 14). São Paulo, naquele momento, vivenciava a descrença plena em relação ao legado histórico anterior e essa atitude se exprimia na emergência de um tecido cultural renovado, produzido na esteira da modernização abrupta e evidente na transformação da linguagem em vários campos: nas ciências sociais, nas artes plásticas, na poesia, na arquitetura, no teatro, no cinema, na mídia.

Contemporaneamente à ressemantização das linguagens, a cidade ganhou, desde o pós-guerra, inúmeras instituições de cultura, como museus, teatros e cinemas, sendo que nessas duas últimas áreas despontaram iniciativas 
empresariais: a Companhia Cinematográfica Vera Cruz e o Teatro Brasileiro de Comédia (TBC). Concomitantemente, o jornalista Assis Chateaubriand fundou, em 1950, a Rádio e Televisão Tupy. Já a Universidade de São Paulo, que havia sido criada em 1934, ganhava realce no período, por causa dos trabalhos publicados pela primeira geração de professores brasileiros, atestando a emergência da dicção intelectual de cunho acadêmico, na qual os cientistas sociais são exemplos candentes. Esse conjunto variegado de linguagens e instituições redesenha os contornos da cidade, que adquiria ares de metrópole e que rompia o ritmo característico ao conjunto do país.

A escolha de São Paulo como centro da análise para se entender a nova cultura do modernismo que se instalava impõe-se, pois, de imediato. Sem se constituir numa experiência pura e exclusiva, foi nesta cidade que germinou a perspectiva essencial ao novo modernismo, substância cultural heterogênea e múltipla, atrelada a uma realidade crescentemente plural e interligada ao movimento exterior. "O que é manifesto em São Paulo-movimento, pressa, luzes, trânsito, arranha-céus, fábricas, dinheiro - é universal, sem voz ou contorno explícito" (Morse, 1970, p. 353). É no espaço dessa fluidez em conformação que ganha significado a multiplicidade de linguagens escandidas no contexto da cidade, sintoma da fragmentação característica ao modernismo na sua terceira e última fase ${ }^{2}$. Nesse sentido preciso, os modernistas de 1922 estariam na base dessa cultura urbana, por reorientarem o olhar para a captação de ângulos novos da realidade paulistana. Se desde esse momento a questão da cultura é, em São Paulo, um problema iminentemente urbano, nos anos por nós considerados tal simbiose traduziu-se em expressões renovadas, nas quais a criação das instituições da cultura são meros sintomas. Os intelectuais de 22, ao transformarem a cultura numa questão essencialmente urbana, retrataram a vida que se modernizava, mas, sobretudo, construíram uma nova ordem de percepção. E quando a realizaram, abriram sendas para as gerações seguintes concretizarem "uma consciência moderna decisiva” (Morse, 1970, p. 323). Mas a radicalidade das mudanças ocorridas, no decênio de 1950, impõe repensar a tão decantada relação entre cultura e sociedade e, concomitantemente, situar a particularidade dessas expressões. Os próprios produtores culturais não se pensavam como continuadores de qualquer tradição: contrariamente, viam-se como introdutores de ruptura profunda e buscavam construir novas identidades, fato revelador de uma dinâmica desenraizadora ${ }^{3}$. Essa sensação de perda de raízes, que para alguns era percebida de modo profundamente negativo, para outros significava a existência de liberdade de ação nas mais diferentes áreas ${ }^{4}$.

Do ângulo da geração de intelectuais e de artistas que adentram à cena cultural no pós-guerra, trata-se de construir novas formas identificadoras, nascidas na rejeição dos princípios do movimento modernista de 1922, cujo "fïm foi marcado, talvez, pela morte de Mário de Andrade em 1945" (Morse, 1970, p. 348). Já nos anos 30, a transformação literária do período arrematava a perda de hegemonia do grupo, ao emergir outra gramática das obras e dos
2 Marshall Berman divide o modernismo em três fases: a primeira, entre o início do séc. XVI e o fim do XVIII; a segunda, entre 1790 e o início do século XX; a terceira corresponde ao nosso século, onde a modernidade como idéia fragmenta-se, perde nitidez e profundidade com o passado (1987, p. 16-17).

3 Sobre o desenraizamento do tipo metropolitano, ver Simmel (1967, esp. p. 15).

4 A esse respeito, cf. Fernandes (1974b, p. 296-297). 
estilos. "A viagem foi tão forte que acabou atingindo os nomes do modernismo paulista: é o romance, é a poesia, é a crença do último Oswald e o último Mário, entre 30 e 40, movidos pelo desejo agônico de assumir uma outra perspectiva pós-modernista" (Bosi, 1979, p. 149). Ao lado dela, a emergência, ainda nos 30, de um núcleo de pintores de origem imigrante e freqüentemente operária deixa patente que, se a heterogeneidade é o signo, tendências encontram-se presentes ${ }^{5}$. Penetra, assim, um modo distinto de exercitar as atividades culturais e que só se concretizariam no decênio de 1950. Nesse andamento, a palavra moderno passa a absorver conotações diversas daquelas construídas no passado e que, em si mesmas, rejeitam os antigos significados de origem, pois o sentido introduzido não apenas afasta-se do movimento fundador, como também se projeta no futuro entendido na acepção de originalidade, de imagens renovadas que virão. Não por acaso, o folheto distribuído no lançamento da pedra fundamental da sede definitiva do MAM (Museu de Arte Moderna) do Rio de Janeiro em 1954 continha as seguintes frases: "O Museu de Arte Moderna reúne elementos de uma experiência em curso, de um processo criador em atividade, abre um caminho para o futuro examinando e criticando os seus próprios resultados" (apud Arte no Brasil, 1979, p. 895). A revisão permanente como vetor das ações culturais desalojam as linguagens construídas e, por isso, as expressões não se cristalizam e passam a se mover em terreno cediço, numa analogia franca com essa história cujo ritmo foi intensificado e cuja pluralidade é a condição para se pensar a cultura.

No plano social imediato, substituía-se os antigos dominantes e a mobilidade intensificava-se, visível no alargamento dos estratos médios e na presença de um operariado numeroso. Nesses anos, ao mesmo tempo, ao processo de crescimento econômico acopla-se a crença na viabilidade de um país moderno e civilizado. Em larga medida, a cultura abeberou-se nessa fonte otimista ou, quando não, certas obras tematizaram as rupturas sociais ocorridas e tentaram trazer para cena as angústias daqueles socialmente desalojados, tais como apareceram na dramaturgia de Jorge Andrade. Nele, "as energias da cidade são vistas como algo que fermenta e erode a velha ordem agrária; mas também como algo que vem sendo amortecido, esvaziado ou voltado sobre si mesmo, no interior de um ethos que lhe é vagamente hostil" (Morse, 1970, p. 412-413). A tematização do tempo, ao percorrer essa dramaturgia, elucida a adesão ao presente na vida das personagens mais jovens: "O passado é um monstro!", grita um dos moços na peça A escada. Se a persistência do tempo persegue a todos como um espectro, não se pode permitir que ele entre: "É como se fosse a presença de um mundo que estivesse preso em minhas mãos!... Ficam lá dentro, trancados... só se ouvem um murmúrio!... e tenho sempre a impressão de que abrindo esta porta, encontro resposta para tanta coisa que me atormenta... e que não sei bem o que é! Mas, não gosto de abri-la! Não sei bem o que me impede!" (Andrade, 1970, p. 367). O teatro de Jorge Andrade

Sobre a heterogeneidade, cf. Paula (s/d, mimeo, p. 5). recupera a tensão característica de uma cultura que rompe os seus laços com o passado, tentando sepultá-lo e encerrá-lo definitivamente, produzindo, em 
contrapartida, mal-estar frente ao presente. Por essa razão, a dramaturgia de Jorge Andrade tematiza os dilemas de um tecido cultural que altera o sentido do tempo, pois só o revisita para reafirmar a originalidade do imediatamente vivido e a certeza de um futuro promissor. Há uma crítica subjacente aos seus textos, qual seja, a da própria modernidade, tal como se encontra em constituição na São Paulo daquela época ${ }^{6}$.

Esse problema crucial reponta tratado de modo diverso em outros campos do pensamento. A reflexão das Ciências Sociais, nos casos onde a dimensão inovadora é marcante, expõe evidente sincronia com as tendências culturais do momento e compassamento com as percepções dominantes. Reconhece-se a necessidade de superar o peso da história pregressa no mundo novo que nasce. Isto é, a questão diz respeito à sombra projetada pela história. As primeiras teses de Florestan Fernandes e vários outros textos escritos até o fim dos anos 50 e início dos 60 são, em nosso entendimento, exemplos típicos dessa situação, ainda que a forma de retradução não seja uníssona em todos os trabalhos. O que caracteriza as duas teses iniciais do sociólogo sobre os índios tupinambá é, fundamentalmente, um "estilo" de urdir a análise, o qual se revela mais importante do que o resultado obtido, ainda que haja conexão entre o tema e a forma de tratamento.

Desde a tese de mestrado - A organização social dos TupinambáFlorestan põe em andamento uma forma de reflexão sociológica absolutamente comprometida com a idéia universal de ciência e que se exprime num modo de construção do seu discurso. Na sua tese de doutoramento - A função social da guerra na sociedade Tupinambá -, o exercício teórico no campo da sociologia é levado ao limite e o sociólogo afirma: "tenho a convicção de que observei, de modo estrito, a observação alternativa, procurando realizar, através dela, tudo o que é cientificamente desejável fazer-se em tais desenvolvimentos da pesquisa sociológica" (Fernandes, 1970, p. 11-12). A preocupação com a ciência e com os métodos precisos de observação, tidos como universais, transformam esses trabalhos em paradigmas de uma modalidade de saber avançada para o momento e absolutamente adequada aos novos ritmos daquela história. Talvez não seja casual que Florestan tenha escolhido essas sociedades indígenas como tema dos seus primeiros trabalhos, por serem organizações sociais já fora da história e sem presente. De outro modo, a escolha de um assunto como esse revela relações, no plano de sentidos comuns, entre a cultura paulistana da época, a sua trajetória pessoal e o discurso científico por ele manejado.

O próprio Florestan era fruto da mobilidade social ascendente e a sua carreira significava ruptura com a sua origem: uma personagem socialmente desenraizada enfrenta um tema fora de qualquer liame possível com o mundo vigente; um objeto distante no tempo torna-se mais propício ao exercício puro do pensamento, por ficar protegido das injunções perturbadoras da história e mais facilmente aprisionável pelos princípios racionais do conhecimento. $\mathrm{O}$ que se encontra subjacente ao conjunto é a afirmação da sociologia como
${ }^{6}$ Richard Morse encontra, similarmente, nos romances de Machado de Assis uma crítica à modernidade: "Por isso, ele dirigiu seus dardos críticos contra a própria modernidade, reservando tratamento irônico para a sociedade que a acolheria" (Morse, 1995, p. 211). 
ciência diversa da história, pois submetida a princípios próprios: “A maioria dos sociólogos brasileiros está inclinada a pensar que a explicação sociológica deve ser por natureza uma explicação histórica... Mas, ela se vincula, paradigmaticamente, a uma orientação arraigada entre os ensaístas ou os precursores e fundadores dos estudos sociológicos no Brasil" (Fernandes, 1958, p. 45-46). Vale dizer, a compreensão histórica origina-se de uma etapa présociológica, com a qual Florestan não se identifica, uma vez que o seu esforço primordial localiza-se na seara da ciência. Daí a afirmação: "Em pleno progresso, as investigações que se desenvolvem em setores especiais precisam de instrumentos de trabalho, mais que de soluções globais mas transitórias" (Fernandes, 1967, p. 178). O progresso, nessa passagem, refere-se tanto à sua face científica, quanto social.

Em outros textos, Florestan preocupou-se diretamente com a segunda e com o papel das ciências sociais na sua promoção: "A educação poderá formar o novo homem, capaz de compreender e de utilizar, construtivamente, as forças que gravitam no mundo social urbano e metropolitano. No nível da atuação propriamente dita, porém, o homem carecerá de recursos intelectuais novos para perceber como essas forças se manifestam, para explicar a influência delas na preservação ou na alteração da ordem social, e para agir com eficácia sobre as condições ou efeitos delas, suscetíveis de serem controlados de forma deliberada e racional. Tais recursos são fornecidos pelas ciências sociais" (Fernandes, 1974, p. 310). A identificação entre as ciências sociais e a promoção do progresso é explícita, na qual essas disciplinas ocupam, duplamente, o papel de produtos e produtoras da transformação. A razão científica passa a informar a racionalidade da conduta e ambas vicejam no tecido cultural da cidade de São Paulo nos anos 50. A razão supra-histórica da ciência é instrumento de promoção da sociedade moderna e atestado da promessa do futuro. Possivelmente, encontram-se no mesmo registro os estudos de comunidade realizados por Emílio Willems e Donald Pierson, nos quais os autores acabam construindo um quadro orgânico e estático dessa vida social, já que a mudança é exogenamente concebida (cf. Willens, 1947; Pierson, 1951).

$\mathrm{Se}$ as análises sobre as comunidades transformaram-se em referências necessárias nesse momento de construção do moderno pensamento sociológico entre nós, o caráter ahistórico do tratamento conferido é revelador da propriedade desse discurso naquele contexto, o que viabilizou a absorção dos paradigmas da sociologia estrangeira, especificamente da Escola de Chicago. O sintoma dominante atesta as transformações da linguagem da cultura em São Paulo. A presença da crítica cultural de corte acadêmico e profissionalizado é exemplo flagrante ${ }^{7}$. No mesmo diapasão, renova-se a linguagem poética a partir do concretismo, inaugurado com a antologia Noigrandes, publicada em 1952, da qual participaram Haroldo de Campos,

A respeito da crítica acadêmica e de cunho profissional, cf. Pontes (1996).
Augusto de Campos e Décio Pignatari, que ainda se expressavam em versos. Com as antologias Noigrandes 2, 3, e 4, editadas em 1955, 1956, 1958, “o grupo se põe a pesquisar numa linha de sintaxe espacial abandonando 
polemicamente o verso" (Bosi, 1977, p. 528). O concretismo poético afirmase na recusa à expressão, aos temas e às dimensões estetizantes características dos anos 40. O poema identificado como objeto de linguagem põe no centro "e de modo radical, a definição da arte como techné, isto é, como atividade produtora" (Bosi, 1977, p. 529). Essas tendências parecem caminhar pari passu com a cultura racionalista, respaldada no princípio de valorização do progresso, característica da cidade naqueles anos. Não por acaso, o concretismo é um fenômeno tipicamente paulistano e profundamente enraizado em São Paulo. A expressão seca e desnuda apartada da sonoridade, do ritmo frásico e dos significados metafóricos, se filia a poesia concreta àquelas experiências - futuristas e cubistas - que se propõem a ultrapassar o simbolismo, tornam-na identificada com as imagens que pululam no mundo contemporâneo (cf. Bosi, 1977, p. 534-535).

Há, pois, fortes relações entre a precisão científica da sociologia de Florestan e a poesia concreta. Mutatis mutandis, ambas objetualizam a vida social ao transformá-la em realidade desvestida, passível, no primeiro caso, de ser explicada por um discurso que vem informado pelas regras do conhecimento correto e por técnicas adequadas; e, no segundo, por referências oriundas da tradição tecnicista. Em ambas, essa recusa diante do legado anterior; nas duas, essa presença da nova sociabilidade que impregna a cidade, ligada a uma percepção diversa do mundo. Enquanto esse pensamento sociológico origina-se da razão científica moderna, o concretismo inspira-se "na moderna cultura da imagem" (Bosi, 1977, p. 536), tributária daquela modernidade nascente em São Paulo, da qual a televisão e o desenvolvimento da publicidade constituem-se em exemplos inegáveis ${ }^{8}$.

Foi no âmbito das artes plásticas, no entanto, que o concretismo provocou as mais acerbas polêmicas, que se expressaram nas querelas em torno do figurativismo e do abstracionismo, radicalizando-se com organização dos grupos concretos Ruptura (1952) em São Paulo e Frente (1953) no Rio. "A predominância de uma grande pintura expressionista, em geral de cunho social, muitas vezes de dimensões monumentais - Segall e Portinari, por exemplo; a presença muito característica, de outro lado, de uma pintura singela, mas não menos atenta ao conteúdo - paisagens e casarios dos bairros populares de São Paulo - representada pela Família Artística Paulista ("pintores e escultores que, embora modernos, se recusavam a quaisquer compromissos com as deliciosas e decadentes brincadeiras abstracionistas', no dizer de Sergio Milliet), eram, entre tantos outros, obstáculos que tornavam difícil nossa adesão à arte abstrata. A resistência por parte dos artistas e críticos a este tipo de arte era de tal ordem que uma artista como Vieira da Silva, radicada no Rio de Janeiro, de 1940 a 1947, foi relegada a um quase ostracismo pela incompreensão geral. Milliet, por exemplo, então um dos nossos maiores críticos, mostrava-se extremamente reticente em relação a toda arte pós-cultista e, a exemplo de Mário de Andrade, condenava a aventura abstracionista como 'intelectualista', 'contorcionista', 'egoísta', etc.” (cf. Arantes, 1991, p. 41).
${ }^{8}$ Nos anos 50, a publicidade brasileira sofistica-se: os criadores usurpam o lugar dos redatores e a concepção dos anúncios passa a envolver uma noção global, como unidade criativa (cf. Arruda, 1985, esp. p. 103). 
Isto é, a consideração da chamada questão do abstracionismo tornava-se inescapável, não só porque minava o prestígio de artistas consagrados, mas também porque a problemática social havia adentrado o universo artístico, até como legado do modernismo. "Ora não custa lembrar que o auge do modernismo fora nacionalista, e o segundo tempo, francamente social" (Arantes, 1991, p. 42). Para um pintor como Di Cavalcanti, "o mundo pertence ao artista quando ele o domina socialmente, quando ele o representa (pelo instinto ou pelo conhecimento) como os outros homens desejariam vê-lo ou poderiam vê-lo se possuíssem meios de representá-lo. A verdadeira obra de arte é uma síntese" (Di Cavalcanti, s/d, p. 245).

Era outro o projeto artístico dos concretistas, no qual enfatizava-se "o primado da visualização, que reduz as formas e cores a elementos da estrutura da dinâmica visual, em detrimento da expressão, da significação da forma e da preocupação temática, está explícito, por exemplo, na recusa de usar expressivamente a cor..." (Favaretto, 1993, p. 9). Essa arte tematicamente despojada, cristalizada nos anos 50, reorientou a linguagem plástica e ampliou os recursos formais. Daí a afirmação de um abstracionista como Flexor: "O quadro abstrato não pretende evocar senão a si mesmo. Nada ele representa, pois ele próprio é uma presença. Não está em função de aparências exteriores a ele, mas conceitua-se como um conjunto de suas próprias funções" (Flexor, 1955). Novamente, o primado da imagem, da forma sobre a representação do conteúdo, da expressão que se auto-referencia, dessa existência em si, desse tempo presente. Talvez por essa razão, Sergio Milliet ao apresentar a Mostra de Flexor, no MAM do Rio de Janeiro, em agosto de 1955, pôde escrever: "Afirma Flexor que sua orientação decisiva no sentido da abstração decorreu não somente de um processo intelectual mas também da contemplação cotidiana do espetáculo que oferece o desenvolvimento frenético de São Paulo, 'onde tudo tende para o futuro e clama seu desprezo pelo passado colonial'. Haveria assim, em seu sentir, uma ligação íntima entre as forças progressistas da civilização e a realização dos pintores, libertados da imitação da natureza, emancipadas das convenções e das tradições, estes, mais do que quaisquer outro, seriam a expressão natural da civilização atômica" (Milliet, 1955).

O abstracionismo, na concepção dos seus adeptos e promotores, é visto como a arte que exprime "a maneira de viver do homem do século vinte" (Pedrosa, 1955). Quer dizer, alteram-se os sistemas de representação que passam a estar sincronizados com o novo mundo. Para um autor como Ronaldo Brito, "a arte moderna, em seus conceitos fundamentais, só veio de fato ser compreendida e praticada a partir da vanguarda construtiva... Foi na década de 50 que o meio de arte brasileiro começou a lidar com os conceitos da arte moderna e as implicações dele advindas, seja crítica ou produtivamente" (Brito, 1985, p. 32). Segundo esses termos, a linguagem artística no Brasil compassouse à dinâmica da modernidade plástica nesse momento, o que implica considerar as expressões anteriores como pré-modernas. De modo semelhante, o 
pensamento da sociologia nascente identificava a produção anterior como présociológica, pré-científica, pré-ensaística e excessivamente historicizada. No projeto dos concretistas paulistas ocorria, similarmente, a conexão entre arte e industrialização, entre forma e produto, criando "uma positividade modernoconstrutivista baseada na crença no progresso contínuo da razão e da história" (Favaretto, 1993, p. 13).

A concepção de progresso, aliada à idéia de sociedade moderna, respaldava-se no crescimento econômico do país, especificamente no surto industrial que abrira transformações de vulto na sociedade brasileira, sendo São Paulo a cidade mais profundamente afetada pelas mudanças. $O$ projeto desenvolvimentista, implementado desde o pós-guerra, impulsionava o ritmo das atividades, carreando alterações de monta na estrutura da sociedade. Ocorreu clara coincidência entre o movimento concretista - na poesia e nas artes - e o incremento da produção industrial, que veio a alterar o ritmo da sociedade e a referendar o ideário do progresso como mola propulsora da vida social. De outro lado, a dinâmica industrial, extremamente intensificada, carreou a ilusão de que o Brasil construiria os pilares de uma moderna sociedade, tributária do desenvolvimento. As correntes estéticas construtivistas e as instituições artísticas, como os museus e as bienais, se exprimem a internacionalização da linguagem, prendem-se ao "surto de industrialização ocorrido no pós-guerra, que levará a uma identificação maior da arte com a tecnologia" (Klabin, 1985, p. 46). No caso específico de São Paulo, a afirmação da arte como produto (segundo o manifesto de Waldemar Cordeiro de 1956, publicado na revista Arquitetura e Decoração) abria o acesso às artes gráficas, à publicidade, ao design industrial e à decoração arquitetônica, revelando as relações entre os artistas e setores do empresariado paulista (cf. Amaral, 1982, p. 78).

A fração mais moderna da burguesia industrial da cidade esteve intimamente ligada à promoção da cultura, quer construindo instituições, como a MAM de São Paulo, criado por Francisco Matarazzo Sobrinho, o MASP (Museu de Arte de São Paulo), por Assis Chateaubriand, o TBC por Franco Zampari, engenheiro das indústrias Matarazzo, e a Vera Cruz, por Cicillo Matarazzo, quer por meio do exercício do mecenato, apoiando artistas, doando obras, comprando peças artísticas. O MAM de São Paulo, particularmente, desenvolveu uma ação decisiva na mudança da linguagem plástica, por meio das exposições e, sobretudo, das bienais. A mostra de Max Bill no MAM paulista, em 1950, é momento indelével na emergência da arte concreta no Brasil. Durante a I Bienal, o primeiro prêmio internacional foi concedido a Max Bill, cuja escultura Unidade Tripartida* provocou grande impacto entre os novos artistas; o primeiro prêmio nacional, similarmente, ficou com Ivan Serpa, que apresentou um quadro concretista (cf. Klabin, 1985, p. 46). As bienais funcionaram, assim, como êmulos da nova linguagem e, nesse campo, a II Bienal, a do IV Centenário, consagrou definitivamente o abstracionismo, ao construir salas especiais a Paul Klee, a Alexander Calder, a Piet Mondrian,

A obra fez parte do acervo do MAC USP. 
além de contar com os pintores abstratos americanos (cf. Lourenço, 1990, p. 372). Mediante esses eventos, o abstracionismo firma-se como expressão legítima entre nós, para cujo consórcio a atuação do crítico Mário Pedrosa, no Rio, foi incontestável.É fundamental reter, no entanto, que as transformações no âmbito da cultura não ganhariam tal relevo sem a atuação dos mecenas.

Nessa linha de raciocínio, a análise de Maria Rita Galvão a respeito da fundação da Companhia Cinematográfica Vera Cruz orienta-se no sentido de estabelecer as conexões entre a nova fração da classe dominante em São Paulo e a sua ação cultural. "Trata-se, então, de refletir sobre o significado de toda uma atitude nova da burguesia paulista em face da cultura" (Galvão, 1981, p. 12). Ou seja, é parte integrante do problema entender como essa camada emergente passa a financiar a cultura e como esse empreendimento liga-se a um movimento de ascensão e de busca de legitimação. Naturalmente, está ocorrendo em São Paulo uma substituição dos antigos mecenas, sintoma de deslocamento, ou perda de exclusividade, dos grupos tradicionais e manifestação de transformação das atividades produtivas. A autora localiza os agentes envolvidos nessas iniciativas: "um pequeno grupo de burgueses em que se misturam a antiga elite da terra e a elite mais recente de origem italiana e que incorpora à velha intelectualidade oficial burguesa uma nova intelectualidade surgida quer do seu seio quer das classes médias" (Galvão, 1981, p. 14-15).

Vale dizer, existiu, neste momento, uma junção entre os ascendentes, a antiga elite intelectualizada e esses novos intelectuais de classe média, em especial os formados pela Faculdade de Filosofia da USP. A criação do MAM, por exemplo, contou com a ação decisiva de Sérgio Milliet, de Lourival Gomes Machado, além de vários outros que se firmavam na cena intelectual paulista. No mesmo andamento, o TBC construiu o profissionalismo teatral e modernizou as artes cênicas no Brasil, cujas novas técnicas, a rigor, haviam sido postas em prática na encenação do Vestido de Noiva, de Nelson Rodrigues, realizada por Ziembinski no Rio, em 1943 (cf. Magaldi, 1962, esp. p. 14). De qualquer modo, o novo surto do teatro em São Paulo nasceu da ação de Franco Zampari, que o organizou no feitio de uma companhia empresarial (cf. Guzik, 1986). O mesmo formato foi implementado na Vera Cruz, na tentativa de fixar um cinema de cunho industrial (cf. Galvão, 1981). As duas instituições, construídas pelo mesmo grupo, vicejaram nas mãos de profissionais estrangeiros - diretores e cenógrafos, por exemplo - sobretudo os de origem italiana, deixando a entrever o quanto a cultura em São Paulo se internacionalizava. Reversivamente, no plano da dramaturgia, a produção de autores brasileiros diferenciava-se e adensava-se, durante os anos 50, quando "foram surgindo as peças que o nosso teatro reclamava para completar a sua maturidade"(Almeida Prado, 1988, p. 61). Em todos os campos o diálogo estabeleceu-se, revelando a presença de uma cultura cosmopolita. Na São Paulo daquele momento o cosmopolitismo manifestava-se como o ideal a ser perseguido (cf. Meyer, 1991, p. 49). 
As obras realizadas por Oscar Niemeyer e sua equipe, no Parque do Ibirapuera, para sediar a exposição do IV Centenário da cidade, são exemplares do movimento arquitetônico moderno que passa a guiar a imagem de progresso urbano. A cidade-metrópole torna-se objeto de remodelações e mudanças planejadas, indicando que a concepção urbana "deixa de ser um problema de 'população' e passa a ser sobretudo um dado da cultura"(Meyer, 1991, p. 49). Com a construção do Ibirapuera, a cidade parece selar a sua imagem de metrópole moderna, civilizada, nascida da intervenção urbanística racional. As construções do projeto comemorativo acabam criando não somente nova feição de urbanização, mas sobretudo erigem uma cidade modernista dentro da metrópole, na qual se impõem como marco decisivo. No conjunto dos edifícios, o Palácio das Indústrias sobressai por suas dimensões, "maior do que o dos Estados e o das Nações, com 250 metros X 50 metros, o que lhe favorece a sensação de esbeltez" (Lourenço, 1990, p. 363). Em meio às inúmeras atividades realizadas, artistas, profissionais universitários, escritores participam ativamente das comemorações e das exposições, estabelecendo fortes elos entre a dinâmica da cidade moderna e a cultura, entre os empreendimentos industriais e os produtores culturais (cf. Lourenço, 1990, p. 392395). Os projetos da arquitetura moderna introduziram o planejamento como princípio do urbano. Semelhantemente, a sociologia em processo de constituição pensava a ciência social como fonte do planejamento da sociedade, capaz de reorientar e equacionar soluções, tendo em vista a modernização.

Desse modo, a cultura da cidade de São Paulo, nesse meio de século, absorveu a noção do moderno, identificado com o progresso e a formação de um futuro civilizado e internacionalmente articulado, nos mais diferentes campos da expressão. No processo, esse tecido cultural firmou-se em oposição a qualquer tradição, inclinando-se na vertente da rejeição ao passado. Nesse sentido preciso, suspendeu a história, estilhaçando-a em múltiplas linguagens, ainda que produzidas numa experiência social comum, que implicaram na perda de contato com as raízes do próprio movimento modernista paulista. Essa revisão operada guarda profundas relações com a dinâmica global do modernismo na cultura e que, no caso de São Paulo, resultou num vórtice inegável de inovações (Berman, 1987, p. 328-330). As transformações intensas da cidade criaram nos seus habitantes a sensação de um movimento incoercível para frente, e uma cultura renovada era indício desse rumo. Em tal ambiente, vicejou o novo modernismo paulista, expressão do caráter crescentemente internacionalizado da cultura. Esse tecido cultural emerge, pois, num momento de dinamismo da sociedade brasileira, particularmente paulistano, por isso, pôde construir as suas promessas a partir do futuro. Essa cultura burguesa do progresso modelou os seus intelectuais e artistas, apurou os seus sentidos em direção aos ares do mundo e gestou problemas que se manifestarão já no final do decênio e se cristalizarão no início da nova década. A perda de intensidade dessa história refez o trajeto da cultura, visível nas hesitações em prosseguir o caminho já trilhado. O sociólogo Florestan Fernandes retoma 
Recebido para publicação em julho/1997

UNITERMIS:

culture,

São Paulo, new modernism, 50 's. a análise do passado brasileiro, para entender os desafinamentos da nossa história; no início dos 60, a crise instala-se entre as vanguardas construtivistas (cf. Favaretto, 1993, p. 17); as instituições de arte vão para o abrigo do Estado; as iniciativas empresariais fenecem. Ironicamente, os impasses da história brasileira redirecionaram os destinos de uma cultura que se afirmou contra eles.

ARRUDA, Maria Arminda do Nascimento. Metropolis and culture: new São Paulo modernism in the middle of the century. Tempo Social; Rev. Sociol. USP, S. Paulo, 9(2): 39-52, october 1997.

ABSTRACT: The article aims at analysing culture in the city of São Paulo in the middle of the century by emphazising the singular character of the languages during this period. Specificity results of the presence of a plural cultural network in which the own intellectuals and artists saw themselves as introducers of deep ruptures in relation with the legate of the modernism of the 20ies. Without being an exclusive, pure experience, in the city of São Paulo there was brought about an essencial perspective which could be called new modernism, supported by a heterogeneous and multiple cultural substance, related to a reality interconnected with the exterior movement. São Paulo's culture during this period identifies itself with the conceptions of progress, of the possibility of building up a civilized and internationally articulated future in the various fields of expression: in the social sciences, in arts, in poetry, in architecture, in theater, in cinema, in media.

\section{REFERÊNCIASBIBLIOGRÁFICAS}

Almeida Prado, Décio. (1988) O teatro brasileiro moderno. São Paulo, Perspectiva.

Amaral, Aracy A. (1982) Arte e meio artístico. Entre a feijoada e ox-burguer. São Paulo, Nobel.

Andrade, Jorge. (1970) A escada. In: . Marta, a árvore e o relógio. São Paulo, Perspectiva.

Arantes, Otília Beatriz Fiori. (1991) Mário Pedrosa: itinerário crítico. São Paulo, Scritta.

ArrudA, Maria Arminda do Nascimento. (1985) A embalagem do sistema: a publicidade no capitalismo brasileiro. São Paulo, Duas Cidades. 
Arte no Brasil. (1979) Vol. 2. São Paulo, Abril Cultural.

Berman, Marshall. (1987) Tudo que é sólido desmancha no ar. A aventura da modernidade. Tradução portuguesa. São Paulo, Companhia das Letras.

Bosi, Alfredo. (1977) História concisa da literatura brasileira. $2^{\mathrm{a}}$ edição. São Paulo, Cultrix.

- (1979) Moderno e modernista na literatura brasileira. Temas, São Paulo, Editora Ciências Humanas, 6.

Brito, Ronaldo. (1985) Neoconcretismo. Vértice e ruptura do projeto construtivo brasileiro. Rio de Janeiro, Funarte.

Di Cavalcanti, Emiliano. (s/d) Realismo e abstracionismo. Fundamentos, São Paulo, 3.

Favaretto, Celso F. (1993) Anos 50-60: "modernidade, vanguarda, participação". Projeto História social das artes plásticas no Brasil (1920-1945). São Paulo, Idesp. mimeo.

FERnANDES, Florestan. (1958) O padrão de trabalho científico dos sociólogos brasileiros. Belo Horizonte, Edição da Revista Brasileira de Estudos Políticos.

. (1967) O método de interpretação funcionalista na sociologia. In: Fundamentos empíricos da explicação sociológica! $2^{a}$ edição. São Paulo, Companhia Editora Nacional.

. (1970) A função social da guerra na sociedade Tupinambá. $2^{a}$ edição. São Paulo, Editora Pioneira.

(1974a) Caracteres rurais e urbanos na formação e desenvolvimento da cidade de São Paulo. In: . Mudanças sociais no Brasil. Aspectos do desenvolvimento da sociedade brasileira. $2^{\mathrm{a}}$ edição. São Paulo, Difel.

. (1974b) O homem e a cidade metrópole. In: Mudanças sociais no Brasil. Aspectos do desenvolvimento da sociedade brasileira. $2^{\mathrm{a}}$ edição. São Paulo, Difel.

FleXor, S. (1955) Flexor. Catálogo da exposição do Museu de Arte Moderna do Rio de Janeiro. Rio de Janeiro, agosto.

Galvão, Maria Rita. (1981) Burguesia e cinema: O caso Vera Cruz. Rio de Janeiro, Editora Civilização Brasileira.

GuZIK, Alberto. (1986) TBC: Crônica de um sonho. São Paulo, Perspectiva.

KLABIN, Vanda Mangia. (1985) A questão das idéias construtivas no Brasil: O momento concretista. Revista Gávea, Rio de Janeiro.

Lourenço, Maria Cecília França. (1990) Maioridade do moderno em São Paulo. Anos 30-40. São Paulo. 505 p. Tese (Doutorado). Faculdade de Arquitetura e Urbanismo da Universidade de São Paulo. 
Magaldi, Sábato. (1962) Panorama do teatro brasileiro. Rio de Janeiro, Funarte-MEC.

Meyer, Regina, M.P. (1991) Metrópole e urbanismo - São Paulo anos 50. São Paulo. 290 p. Tese (Doutorado). São Paulo, Faculdade de Arquitetura e Urbanismo da Universidade de São Paulo.

Milliet, Sergio. (1955) Catálogo da exposição do Museu de Arte Moderna do Rio de Janeiro. Rio de Janeiro, agosto.

Morse, Richard M. (1970) Formação histórica de São Paulo (da comunidade à metrópole). São Paulo, Difel.

. (1995) As cidades "periféricas" como arenas culturais. Estudos Históricos 16. Cultura e História Urbana, Rio de Janeiro, Editora da Fundação Getúlio Vargas, julho-dezembro.

Paula, Maria Lúcia Bueno Coelho. (s/d) Os mundos da arte de Milton Dacosta. São Paulo, Idesp. mimeo.

Pedrosa, Mário. (1955) Vanguarda da escola de Paris. Espaço, Rio de Janeiro, Museu de Arte Moderna do Rio de Janeiro. março.

Pierson, Donald. (1951) Cruz das Almas. A Brazilian village. New York/ Washington, Smithsonian Institute.

Pontes, Heloísa. (1996) Destinos mistos. O grupo Clima no sistema cultural paulista (1945-1968). São Paulo. 368 p. Tese (Doutorado). Faculdade de Filosofia Letras e Ciências Humanas da Universidade de São Paulo.

Schorske, Carl E. (1988) Viena fin-de-siècle. Política e cultura. São Paulo, Editora Unicamp/Companhia das Letras.

Simmel, Georg. (1967) A metrópole e a vida mental. In: Velho, Otávio G. (org.). O Fenômeno urbano. Rio de Janeiro, Zahar.

Willems, Emílio. (1947) Cunha. Tradição e transição em uma cultura rural no Brasil. São Paulo, Secretaria da Agricultura. 